\title{
COORDENAÇ̃̃O ENTRE POLÍTICAS MACROECONÔMICAS: O ESTABELECIMENTO DE UM DO CONSENSO E SUAS LIMITAÇÕES
}

\section{COORDINATION OF MACROECONOMIC POLICIES: THE ESTABLISHMENT OF A CONSENSUS AND LIMITATIONS}

\author{
Karlo Marques Junior \\ Departamento de Economia UEPG - Universidade Estadual de Ponta Grossa - PR \\ karlomjunior@hotmail.com
}

Submissão: $28 / 05 / 2019$

Aprovação: 29/06/2021

\section{RESUMO}

Este artigo tem como objetivo resgatar o debate macroeconômico ocorrido nas últimas décadas sobre a coordenação entre as políticas monetária e fiscal e as suas consequências em termos de aplicações de políticas. Para isso, uma revisão da literatura recente que permeia o tema foi preparado.

Palavras Chaves: Coordenação entre política fiscal e monetária; Dominância Fiscal; Regras de Política Monetária

\begin{abstract}
This article aims to rescue the debate occurred in economics about the coordination between monetary and fiscal policies and their consequences in terms of policy applications. For this, a review of recent literature that permeates the subject has been prepared.
\end{abstract}

Key words: coordination between fiscal and monetary policy; Fiscal dominance; Monetary Policy Rules.

\section{Introdução}

Nas últimas décadas, foi possível observar um relativo consenso no que se refere ao papel das políticas macroeconômicas. Em linhas gerais, esse consenso versava que a autoridade monetária deveria atuar por meio de regras claras e críveis, utilizando-se de um único instrumento, a taxa básica de juros, para atender a uma meta principal, a estabilidade de uma taxa de inflação em nível reduzido. A política fiscal, por sua vez, teria um papel secundário de oferecer subsídios aos objetivos da política monetária, mantendo superávits primários grandes o suficiente para não pressionar a inflação e para que a autoridade monetária não se deparasse com a necessidade de financiar uma possível situação de insolvência do setor público.

Dentro desse contexto, seria desejada uma mobilidade de capitais ampla, para que a economia se beneficiasse, através do processo de arbitragem, da liquidez internacional. Desta 
forma, países em que o capital fosse escasso poderiam atrair recursos para fazer frente às suas demandas por investimentos, enquanto os capitais de países em que estes se encontram em relativo excesso, poderiam se beneficiar de taxa de juros mais altas encontradas no primeiro grupo. Como consequência dessa elevada mobilidade financeira e da possibilidade de gerir a política monetária, a taxa de câmbio deveria flutuar da forma mais livre possível.

Emergiu desse relativo consenso, no qual a política monetária tem como objetivo principal manter a inflação estável através da manipulação da taxa de juros, um conjunto de propostas visando orientar a gestão da política monetária, o qual ficou conhecido como Regime de Metas de Inflação. Tal regime foi implantado por diversos países a partir da década de 1990, de forma explícita ou implícita. Como veremos a seguir, a sua eficácia é bastante sensível às condições físcais da economia, sendo, dessa forma, necessário compreender efetivamente as relações entre ambas as políticas macroeconômicas, monetária e fiscal, para que seja possível uma maior compreensão do comportamento das economias atuais.

Contudo, com o advento da crise financeira internacional da segunda metade dos anos 2000, o consenso em destaque passou a ser questionado, levantando as limitações das regras estabelecidas e especulações a respeito de como se configuraria uma nova agenda de pesquisa a respeito do tema em questão. Em geral, essas considerações apontam não na direção de uma ruptura de paradigma, mas de ajustes que possibilitariam uma sintonia fina no conhecimento das relações econômicas exploradas na literatura macroeconômica.

Feitas tais considerações, o objetivo do presente artigo é fazer uma revisão teórica didática a respeito da coordenação entre política monetária e fiscal, apontando suas relações e relevância destas relações para a eficácia de tais políticas econômicas. Adicionalmente, será feita uma breve discursão dos possíveis caminhos para a pesquisa na área de conhecimento em particular.

Entender como se posiciona a ciência econômica, é fundamental para entender as decisões dos policymakers e consequentemente, é de grande auxílio para a compreensão da gestão das políticas públicas. Desta forma, as experiências na condução do regime de metas inflacionárias em muitos países vêm mostrando que o arcabouço operacional da política econômica está associado a medidas não só de cunho monetário, mas a busca pelo equilíbrio fiscal nas contas públicas. Isto porque um desequilíbrio na situação fiscal de uma determinada economia pode elevar os serviços da dívida pública e proporcionar uma perda no controle da inflação por parte da política monetária ou exigir um sacrifício maior em termos de elevação da taxa básica de juros.

Com intuito de apresentar as relações introduzidas acima, o artigo está dividido do seguinte modo: a seção dois trata das relações de dependência entre política monetária e fiscal, iniciando com uma breve digressão a respeito da concordância estabelecida em torno do papel da política monetária e sua relação com o movimento do nível de preços; a terceira seção busca levantar quais pontos referentes a essas políticas se tornaram alvo de questionamento no pós-crise e os possíveis caminhos que tal linha de pesquisa pode adotar nos próximos anos. Por último, é apresentada uma seção que sintetiza o debate. Essa, por sua vez, visa, mais do que chegar a conclusões rigorosas, apontar caminhos que devem ser explorados quando se trata das interrelações entre políticas macroeconômicas que possibilitam a estas atingir seus objetivos.

\section{COORDENAÇÃO ENTRE POLÍTICA MONETÁRIA E POLÍTICA FISCAL: O CONSENSO ESTABELECIDO.}

Lançando mão da hipótese de que há um consenso de que é desejada uma inflação baixa e estável (CARLIN e SOSKICE, 2006), temos o contexto em que a experiências na condução 
do regime de metas inflacionárias em muitos países vêm mostrando que o arcabouço operacional da política econômica está associado a medidas não só de cunho monetário, mas à busca pelo equilíbrio fiscal nas contas públicas.

Dessa forma, uma série de trabalhos chama a atenção para a relação entre política fiscal e política monetária, apontando que, em um regime de metas de inflação, em que existe uma regra monetária aos moldes da de Taylor (1993), não se podem ser desprezadas pelo Banco Central, algumas importantes variáveis fiscais. Ou seja, não se pode desprezar o fato de que o comportamento da política fiscal, estipulado pelo Tesouro, afeta também a política monetária. Além disso, como o próprio funcionamento da política monetária impacta a política fiscal através do aumento do serviço da dívida- tem-se que a coordenação entre ambas se mostra necessária.

Em suma, caso a autoridade fiscal opere sem respeitar sua restrição intertemporal, a autoridade monetária pode se ver obrigada a recorrer à senhoriagem para saldar os passivos assumidos pelo setor público. Por outro lado, o Banco Central ao determinar o nível da taxa de juros, deve estar atento à trajetória intertemporal da dívida, uma vez que taxas elevadas encarecem a dívida financeira do Tesouro Nacional.

Dadas as considerações acima, temos na sequência, uma análise sobre a coordenação entre políticas monetária e fiscal realizada a partir de uma revisão da literatura acadêmica, sobretudo de um recorte que trata das relações de dominância monetária e dominância fiscal. Mais precisamente, na busca de elucidar tal debate, será feita uma exposição da literatura selecionada a respeito da condução da política monetária e, posteriormente, da sua interação com a política fiscal.

\subsection{POLÍTICA MONETÁRIA E INFLAÇÃO.}

Para uma melhor compreensão da recente literatura que trata das relações entre política monetária e fiscal, é interessante tratar sobre como se configurou a concepção hegemônica do papel da política monetária e como esta deve ser operacionalizada pela autoridade monetária. Será destacado como a visão de que a política monetária é neutra no curto prazo, no sentido de afetar variáveis reais, conduziu a um consenso de que sua operação deveria ser realizada através de regras em detrimento de uma condução discricionária. De fato, compreender os objetivos e operacionalização desta política é fundamental para compreender também como ela se relaciona com a política fiscal.

O fenômeno da inflação é tradicionalmente interpretado pelos economistas como sendo um fenômeno monetário. Baseado em relações empíricas, Walsh (2003) discorre sobre a correlação positiva de longo prazo entre inflação e taxa de crescimento da moeda ${ }^{1}$. Uma segunda conclusão que emergiria de estudos empíricos, porém não tão robusta quanto a primeira, seria a inexistência de um efeito de longo prazo entre a taxa de crescimento da moeda e o crescimento do produto real. Nesse caso, encontram-se evidências de efeitos positivos brandos entre a aceleração do processo inflacionário e crescimento em países com baixa taxa de inflação, por um lado, e a ausência desse efeito para países com altos índices de inflação. Segundo Romer (2012), esse fenômeno pode ocorrer porque o custo marginal da inflação é baixo se a inflação esperada é pequena.

\footnotetext{
${ }^{1}$ Os autores fazem referências a estudos empíricos em que tal correlação é bastante próxima da unidade, com pequenas variações que dependeriam da definição que se faz sobre moeda. Porém, essa alta correlação não demonstraria necessariamente uma relação de causalidade, caso houvesse outro fator gerador da inflação e o banco central permitisse o crescimento da taxa de moeda para fazer o ajuste com o crescimento do nível de preços. Em outras palavras, a causalidade só existira no caso em que a oferta de moeda fosse exógena.
} 
A ausência de um efeito duradouro da inflação sobre o crescimento econômico pode ser atribuída ao papel das expectativas dos agentes em relação ao comportamento dos preços, o que contradiz a ideia de que permanentes choques monetários resultariam em permanentes mudanças no crescimento de variáveis reais ${ }^{2}$. Em outras palavras, se a inflação já é antecipada pelos agentes, o que é mais provável em um ambiente de alta inflação, o efeito de variáveis nominais sobre variáveis reais seria nulo e, consequentemente, o efeito da política monetária seria restrito às variáveis nominais, tais como o nível de preços.

Outro fator importante para se compreender a política monetária, é a relação entre taxa de juros, inflação e moeda.

Tal questão pode ser sumarizada, como visto em Walsh (2003), pela equação de Fisher, que estabelece uma igualdade ente a taxa nominal de juros e a soma da taxa real de juros com a taxa de inflação esperada, isto é:

$$
i=r+\pi^{e}
$$

Dentro deste contexto, destacado pelo autor, considerando que a taxa real de retorno é independente da inflação, deve haver uma relação de longo prazo positiva entre a taxa nominal de juros e a inflação esperada e, consequentemente, com a taxa de crescimento do estoque monetário.

Tais evidências agem no sentido de tentar corroborar dois corolários fundamentais da economia monetária: i) variações no estoque nominal de moeda não afetam, no longo prazo, variáveis reais, como nível de desemprego, produto real e taxa de juro real; e consequentemente, ii) o objetivo primordial da política monetária deve ser o de garantir a estabilidade do nível de preços.

Como consequência dos corolários reproduzidos acima, desenvolveu-se um amplo debate a respeito da forma com que policymakers devem operacionalizar a política monetária. Em geral, a visão que prevaleceu entre os economistas acadêmicos, do setor público e de outras esferas, foi a de que se deveria optar por regras pré-estipuladas de política, em detrimento de políticas discricionárias, uma vez que estas últimas, como explicado a seguir, poderiam se apresentar dinamicamente inconsistentes.

Sendo assim, diante de um viés inflacionário por parte do governo, o Banco Central teria independência para operar uma política monetária cujo objetivo principal fosse manter a estabilidade do nível de preços.

\section{Regras Versus Discricionariedade.}

O debate entre regras e discricionariedade na a operação da política monetária ganha maior relevância após Milton Friedman lançar mão da chamada curva de Phillips aceleracionista, cuja ideia principal é a de que o trade-off entre inflação e desemprego, contido na curva de Phillips Keynesiana, não era de natureza permanente, mas sim causado por uma ilusão monetária.

Uma vez que o mercado de trabalho estivesse no nível de equilíbrio entre oferta e demanda e, portanto, a economia produzindo de acordo com seu potencial, o que seria condizente à taxa natural de pleno emprego, um aumento do estoque de moedas elevaria os preços nos mercados de bens e trabalhos.

Considerando que para Friedman (1997), os agentes tomam suas decisões de forma adaptativa, isto é, utilizando as informações pretéritas, a política expansionista poderia desencadear uma ilusão monetária nos agentes, ou seja, os aumentos nos salários, estritamente

${ }^{2} \mathrm{O}$ autor, porém, afirma que não há um pleno acordo e nem um completo entendimento sobre a relação de longo-prazo entre inflação e demais variáveis reais, tais como produto e emprego. Há, segundo o mesmo, um consenso geral com um pequeno "desacordo" de que o trade-off inflaçãodesemprego não é permanente. 
nominais, poderiam ser interpretados como aumentos reais, impulsionado a oferta de mão de obra e elevando o produto para um valor além do pleno emprego. Ao perceberem, num segundo momento, ter se tratado de um aumento nominal, os agentes adequariam suas expectativas e a economia voltaria para o nível de pleno emprego. Desta forma, a política monetária só seria eficaz nos períodos em que a autoridade monetária mantivesse a ilusão monetária sem que os agentes incorporassem tal estratégia (segundo o autor, tal caso só seria possível por períodos limitados). Porém, a aceleração do processo inflacionário seria o custo a ser pago por tal política.

Sendo assim, um questionamento é lançado por Friedman (1997): qual seria o papel da política monetária? Friedman ressalta que ela deve se restringir a controlar variáveis que lhe são possíveis, isto é, variáveis nominais. Desta forma, ele define como sendo três os papéis da política monetária: i) impedir a própria moeda de ser uma fonte importante de perturbação econômica, de forma que não se deve pisar no freio com muita força e nem ocasionar uma expansão mais brusca que o necessário. ii) Fornecer um pano de fundo estável para economia. É preciso criar um ambiente de credibilidade e confiança quanto ao comportamento futuro do nível de preços, garantindo um melhor funcionamento das atividades econômicas. iii) A política monetária pode contribuir para contrabalancear importantes distúrbios no sistema econômico surgidos de outras fontes. Como por exemplo, trabalhar junto com a política fiscal, impedindo que grandes déficits provoquem surtos inflacionários, além de dar capacidade para o governo financiá-los, aumentando a taxa de juros. Porém é recomendada cautela nesse último ponto, devido ao limitado conhecimento destes distúrbios e da capacidade de solucioná-los via manipulação do estoque monetário.

Considerando a hipótese de que o trade-off entre desemprego e inflação, contido na curva de Phillips, é temporário e "não resulta da inflação per se, mas da inflação inesperada" (FRIEDMAN,1997) e as deliberações a respeito do papel da política monetária, o autor faz menção ao fato de que não se conhece com precisão os efeitos da política monetária sobre o nível dos preços e a defasagem de tempo entre a medida adotada e a ocorrência de tais efeitos. Desta forma, Friedman (1997) propõe uma regra de política monetária baseada em uma taxa de crescimento de um determinado agregado monetário em detrimento das políticas discricionárias.

Uma vez que, para Friedman, a ideia subjacente à política monetária baseada em regras é a de que, ao se adotar publicamente uma meta de crescimento do agregado monetário que fosse condizente com uma inflação moderada, o Banco Central estaria minimizando os efeitos nocivos da ilusão monetária. Sendo que esses efeitos, por sua vez, poderiam levar ao fenômeno que ficou conhecido como estagniflação, a autoridade monetária estaria, dessa forma, contribuindo para a manutenção da estabilidade econômica, facilitando a ação do que, segundo o autor, são as verdadeiras forças que contribuem para o desenvolvimento das variáveis econômicas reais, tais como, engenho, invenção, esforço duro e poupança.

Outro importante grupo de trabalhos que advogam em favor de regras para políticas macroeconômicas, isto porque, desta vez, se faz referência também à política fiscal, são atribuídos à vertente novo-clássica, com destaque para Kydland e Prescott (1977) e posteriormente a trabalhos como Calvo, Barro e Gordon (1983).

A referência utilizada por tal matriz teórica remete à ideia de que os agentes tomam suas decisões com base em expectativas racionais, isto é, ao formar "previsões ou expectativas sobre o valor futuro de uma variável, agentes econômicos racionais irão fazer o melhor (mais eficiente) uso de todas as informações públicas sobre os fatores que eles acreditam determinar tal variável" (SNOWDON et alii, 1994). Desta forma, os agentes irão se antecipar às decisões do policymaker, caso tenham as informações necessárias, e irão manter suas ofertas no mercado de bens e de trabalho em equilíbrio. Consequentemente, como o funcionamento dos 
fenômenos econômicos é conhecido, a política monetária só terá efeito caso surpreenda os agentes, e ainda assim, o efeito se dará apenas no curto prazo.

Uma vez que os agentes são racionais, lança-se mão da hipótese de inconsistência dinâmica da política monetária discricionária. Em suma, uma política é intertemporalmente inconsistente para Kydland e Prescott (1977), quando na busca por resultados ótimos a cada período, acaba por gerar resultados subótimos. Nesse caso, a política ótima só seria consistente se o efeito da política futura fosse ignorado pelos agentes nas tomadas de decisões presentes, ou se as decisões dos agentes não influenciassem a função objetivo social (caso contrário, o ponto consistente é subótimo e o ótimo é inconsistente). Em outras palavras, a tentativa de gerar um produto econômico social ótimo, maior do que o de pleno emprego para um período $t$, não seria sustentável no período $t+1$ porque os agentes voltariam a ofertar produtos e empregos em valor adequado para otimizar suas funções objetivo sujeitas às suas restrições. Sendo assim, tal política é definida como sendo inconsistente intertemporalmente.

Caso o policymaker insista em usar a teoria do controle ótimo para cada período de tempo, na tentativa de surpreender os agentes, essa estratégia se tornaria ineficaz, já que mudanças na regra de política, bem como a expectativa para a política futura, impactam suas decisões. Ou seja, essa estratégia seria absorvida ao conjunto de informações dos agentes econômicos modificando suas funções objetivo e suas funções de restrição.

Pode se concluir, portanto, que a teoria do controle ótimo "não é uma ferramenta apropriada para o planejamento de economias dinâmicas, uma vez que a decisão corrente dos agentes econômicos depende da política esperada para o futuro e essas expectativas não são invariantes ao plano selecionado" (KYDLAND e PRESCOTT, 1997). Os autores vão além, quando afirmam que tal paradoxo também pode surgir em situações em que o funcionamento da estrutura econômica não é bem conhecido, "já que mudanças nas séries relevantes para os agentes tomarem decisões irão gerar variações na decisão ótima, gerando novas expectativas, como colocado na crítica de Lucas" (KYDLAN e PRESCOTT, 1997). Nesse caso, a economia convergiria para um equilíbrio consistente, mas intertemporalmente subótimo.

Sendo assim, "a prescrição padrão de política, é selecionar as melhores políticas dada a situação corrente. Porém, os resultados serão taxas de inflação excessivas, sem nenhuma redução do desemprego. Logo, há uma preferência por regras que mantêm a estabilidade dos preços" (KYDLAN e PRESCOTT, 1997). Mais especificamente, tem-se que, a "confiança na política, tal como crescimento constante da oferta de moeda e taxas de impostos constantes, constitui um curso seguro de ação", devendo o governo optar em segui regras, ao invés de discrição. Em resumo, a solução para o entrave da inconsistência dinâmica seria a adoção de regras claras por parte dos policymakers.

\section{Regime Monetário de Metas De Inflação.}

Entre as prescrições de política monetárias encontradas na literatura, uma merece especial destaque por sua ampla repercussão no âmbito acadêmico e por sua ampla aplicação, direta ou indiretamente, em uma extensa gama de países a partir da década de 1990, incluindo o Brasil em julho de 1999. Trata-se do regime monetário de metas de inflação (inflation targeting).

O regime de metas de inflação é definido nas palavras de Mishkin (2000) como sendo uma estratégia de política monetária que compreende cinco elementos principais: i) O anúncio público de uma meta numérica para a inflação de médio prazo; ii) Um compromisso institucional com a estabilidade de preços, sendo este o objetivo primordial da política monetária, para o qual, as outras metas estão subordinadas; iii) uma estratégia inclusiva de informação, em que muitas variáveis, e não apenas os agregados monetários ou a taxa de câmbio, são usados para decidir a definição de instrumentos de política; iv) maior 
transparência em relação à estratégia de política monetária por meio da comunicação com o público e os mercados sobre os planos, objetivos e as decisões das autoridades monetárias; e v) uma maior responsabilização do banco central para alcançar seus objetivos de inflação.

No regime de metas de inflação, qualquer pressão inflacionária, seja pelo lado da oferta ou pelo lado da demanda, deve ser combatida pela autoridade monetária com o aumento da taxa nominal de juros, seu instrumento de política monetária por excelência (BERNANKE \& MISHKIN, 1997; BERNANKE et al., 1999). Se o aumento da taxa nominal de juros for maior que o aumento da inflação esperada, a taxa real de juros também deve aumentar, promovendo um desaquecimento da demanda agregada pelas vias do consumo e do investimento, o que contribui para que a trajetória da inflação não divirja do intervalo socialmente desejado (sua meta). A referida função de reação da autoridade monetária é conhecida na literatura por Regra de Taylor e exprime, em linhas gerais, o comportamento de grande parte dos Bancos Centrais na atualidade.

Em termos formais, a regra de Taylor (1993) foi sugerida pelo autor em seu seminal artigo Discretion versus Policy Rules in Practice como uma regra de política monetária que fosse condicente com o equilíbrio macroeconômico. Desta forma, seria definida uma função de reação do Banco Central onde a taxa de juros se ajusta de acordo com o desvio do produto de sua taxa potêncial e do desvio da inflação em relação à sua meta, "dando pouca atenção à taxa de câmbio" (TAYLOR, 1993). Tal regra pode ser expressa, genericamente, da seguinte forma ${ }^{3}$ :

$$
i_{t}=\pi_{t}+r^{*}+a_{\pi}\left(\pi_{t}-\pi^{*}\right)+a_{y}\left(y_{t}-y^{*}\right)
$$

Sendo $i_{t}$ a taxa nominal de juros utilizada como instrumento de política monetária e, potanto, fixada pelo governo, $r^{*}$ a taxa real de juros de equilíbrio, $\pi_{t}$ a taxa de inflação corrente, $\pi^{*}$ a meta de inflação. Na sequência, tem-se $y_{t}$ como sendo o produto corrente e $\mathrm{y}^{*} \mathrm{o}$ produto potencial.

Assim, respaldados pelo ceticismo a respeito de se manter um trade-off entre inflação e desemprego a longo prazo, e tendo a confiança no controle inflacionário como pré-condição para o crescimento sustentável ao longo do tempo, vários trabalhos, como Bernanke et al (1999), defendem a capacidade da meta de inflação em atuar como uma âncora nominal para balizar as expectativas dos agentes a respeito da formação de preços.

Portanto, a função de âncora nominal é um dos principais motivos para a implementação do regime de metas. Sem a existência de tal âncora, as expectativas podem apresentar um alto grau de volatilidade, o que pode vir a comprometer a tomada de decisões por parte dos agentes como, por exemplo, a decisão de investimentos.

Seguindo tal percepção acerca dos motivos que levaria a se adotar o regime monetário em destaque, Mishkin (2000) destaca que ao contrário de quando se usa a âncora câmbial, utilizar-se da inflação possibilita que a política monetária volte o foco para a economia doméstica, possibilitando acomodar choques internos. Já em relação ao regime de metas monetárias, aos moldes anteriormente propostos por Friedman, a vantagem do regime de metas de inflação se dâ pelo fato de não ser necessário uma relação estável entre moeda e inflação. Neste último, o governo se utilizaria de todas as informações necessárias para manipular os instrumentos de política monetária, por exemplo, dado a demanda por moeda, o governo pode ajustar a oferta monetária no objetivo de atingir uma taxa de juros em um patamar adequado à não aceleração da inflação- o que poderia ser um problema no regime de

${ }^{3}$ Originalmente, a regra proposta por Taylor consiste em: $r=p+.5 y+.5(p-2)+2$. Sendo ' $r$ ' é a federal funds rate, ' $p$ ' é a taxa de inflação dos últimos quatro trimestres e ' $y$ ' é o desvio percentual do PIB real de sua meta. 
metas monetárias em que houvesse uma aceleração da demanda por moeda. O regime em questão também teria a vantagem de ser mais fácilmente assimilado pelo público.

O regime de metas de inflação também seria favorável à construção de um ambiente institucional em que o Banco Central estivesse menos exposto a um viés inflacionário. Isto porque possibilitaria afastá-lo do viés de aderir uma política dinâmicamente inconsitente e lhe daria mais garantias de uma independência política que o possibilitaria focar no que seria o objetivo de longo prazo da política monetária, ou seja, o controle do nível de preços. Ainda de acordo com Mishkin (2000), o compromisso institucional com a estabilidade de preços seria especialmente relevante em países de mercados emergentes, devido ao histórico de má administração da política monetária.

Porém, muitos autores de diferentes abordagens teóricas chamaram a atenção para a importância do comportamento de variáveis fiscais sobre o comportamento do nível de preços. A razão para isso de daria seja pela influência da política fiscal sobre a monetária, seja sua atuação direta sobre a trajetória da inflação. Como veremos adiante, houve críticas de que o regime de metas de inflação não poderia impedir a dominância fiscal, e que a flexibilidade exigida pelo regime em relação à taxa de câmbio pode levar a uma instabilidade financeira, fatores esses que ganhariam importância num contexto de economias de mercados emergentes. No que se segue, será apresentada uma revisão com foco no debate a respeito de tal tema e uma proposição de uma regra de política que leve em conta tais considerações.

\subsection{COORDENAÇÃO ENTRE POLÍTICA MONETÁRIA E POLÍTICA FISCAL E SEUS EFEITOS SOBRE A INFLAÇÃO.}

Blanchard et al. (2010) chamam a atenção para o fato de que durante as décadas de 1960 e 1970, as políticas monetárias e físcais tinham a mesma relevância e eram geralmente vistas como dois instrumentos para atingir os mesmos alvos, como equilíbrio interno e externo, por exemplo. Porém, nas últimas décadas, a política fiscal ficou para segundo plano e a atenção dos policymakers se voltou principalmente para as questões monetárias. Não obstante, diversos trabalhos se propuseram a estudar as limitações da política monetária, sobretudo quando há um ambiente fiscal hostil.

Em Some Unpleasant Monetarist Arithmetic, Sargent e Wallace (1981) propõem que caso a autoridade fiscal não atenda a restrição intertemporal de longo prazo do governo, haverá a possibilidade de que a política monetária perca sua eficácia no que tange ao controle da inflação. Tal feito ocorreria devido à necessidade de financiar os déficits públicos através da operação de senhoriagem, gerando um imposto inflacionário. Para os autores, a economia pode se comportar de duas formas quando diz respeito às interações entre políticas econômicas: em uma condição de dominância monetária ou de dominância fiscal.

$\mathrm{Na}$ situação em que a autoridade fiscal tem os gastos restringidos pela função de demanda por títulos, de tal forma que seja necessário um superávit que mantenha constante a relação dívida líquida do setor público/PIB (DLSP/PIB) ${ }^{4}$, tem-se uma dominância monetária. Nesse contexto, a autoridade monetária determina a oferta de moeda e os gastos do governo ficam restritos a tal decisão. Em resumo, "é necessário que o orçamento e seus possíveis déficits possam ser financiados por uma combinação de senhoriagem escolhidas pela autoridade monetária e por títulos públicos ofertados ao público" (SARGENT E WALLACE, 1981). Sob esse esquema de coordenação de políticas, a autoridade monetária tem o controle permanente da inflação, dado pela oferta da base monetária. Configura-se, portanto, a situação

\footnotetext{
${ }^{4}$ Em geral, o governo brasileiro utiliza a relação (DLSP/PIB) como indicador de solvência do setor público. Porém, nos países da OCDE essa relação é computada utilizando-se a dívida bruta.
} 
de dominância monetária. Nesse contexto, se diz que a política monetária é ativa e a política fiscal é passiva.

$\mathrm{Na}$ situação de dominância fiscal, temos que "a autoridade fiscal pode definir sua atuação independentemente do seu orçamento, anunciando todos os possíveis déficits e superávits e assim, o montante das receitas deve ser levantado através de senhoriagem e títulos públicos." (SARGENT E WALLACE, 1981). Neste caso, a autoridade físcal desconsidera a necessidade de um superávit que seja suficiente para manter sobre controle a relação DLSP/PIB. Sob essa segunda coordenação, temos o que os autores chamaram de uma "aritmética desagradável". A autoridade monetária torna-se passiva e perde controle sobre inflação, pois é forçada a emitir receitas de senhoriagem necessárias para fazer frente à solvência do governo. A circunstância é particularmente perniciosa quando a demanda por títulos por parte dos investidores, em equilíbrio com a demanda de recursos líquidos por parte do governo, implica em uma taxa de juros superior ao crescimento da economia. Contudo, ainda que a inflação seja gerada por um desequilíbrio fiscal, continua sendo um fenômeno monetário.

Desta forma, pode-se representar a restrição orçamentária do governo como sendo:

$$
g=b^{\prime}+m+t
$$

Em que g são os gastos do governo, b' é a receita do governo adquirida por novos títulos, $\mathrm{m}$ é a receita proveniente da emissão monetária e $\mathrm{t}$ se refere à receita tributária. Considerando que não se mantenha o equilíbrio entre gastos e arrecadação tributária, o governo deve financiar seu déficit via emissão de dívidas, caso não queira se financiar por meio do imposto inflacionário.

Contudo, ainda que a política fiscal deficitária seja financiada no curto prazo pela emissão de títulos públicos, a elevação do principal e dos encargos com juros cria a necessidade de expansão futura da base monetária, caso a restrição intertemporal não seja respeitada.

Isso ocorre devido à existência de um limite superior à demanda por títulos públicos, relativo ao tamanho da economia (ou ao interesse dos investidores em financiar o crescimento da dívida pública. Sendo esse interesse menor quanto maior for a percepção de risco de default. Tal situação será trabalhada na sequência), que impossibilita que o financiamento da dívida pública via emissão de títulos ocorra ininterruptamente no caso da ausência de superávit primário. Dessa forma, uma vez atingido esse limite, o Banco Central se vê forçado a emitir moeda para fazer frente às necessidades fiscais, desencadeando um efeito inflacionário.

Deste modo, em uma situação de dominância fiscal, a política monetária está sujeita a perder a capacidade de controle permanente do nível de preços. Apesar do risco de perder o controle sobre a inflação ser dado por uma deterioração das condições fiscais da economia, a inflação continua sendo um fenômeno monetário, como dito anteriormente, uma vez que é causada pela emissão de moeda. Tal condição é relaxada pela corrente da Teoria Fiscal do Nível de Preços, como exposto a seguir.

Outra importante referência na literatura sobre coordenação entre políticas monetárias e fiscais é atribuída a Leeper (1991). Nesse trabalho, o autor define várias situações em que a política monetária pode ser considerada ativa ou passiva, dependendo da capacidade de respostas a choques da dívida pública.

Em uma política monetária ativa, a autoridade monetária não leva em consideração os choques fiscais, já que se tem um regime fiscal ricardiano. Em outras palavras, tem-se uma política monetária eficaz em seus objetivos de controlar o nível de preços, uma vez que a autoridade fiscal trabalha com condições de financiar seus gastos via receitas tributárias. $\mathrm{O}$ 
caso oposto seria de uma política fiscal ativa, logo, não-ricardiana, e uma política monetária passiva, ambiente em que essa perderia o controle sobre a inflação. Claramente, a primeira situação seria a ideal para se implementar um regime monetário do tipo metas de inflação.

O conceito de regime fiscal Ricardiano definido em Leeper (1991) é análogo à situação definida em Sargent e Wallace(1981) como sendo um regime em que a política monetária será dominante, isto é, um regime em que a autoridade monetária é ativa e a autoridade fiscal é passiva. Nesse caso, distúrbios fiscais não influenciam o preço de equilíbrio, a taxa de juros e os saldos reais. Por outro lado, um regime fiscal não-Ricardiano é análogo ao regime fiscal dominante de Sargent e Wallace, em que a política monetária comporta de maneira passiva e a política fiscal de maneira ativa. Sob esse regime, déficits fiscais elevam a inflação devido à necessidade de um crescimento da oferta de moeda para contrabalancear a insolvência intertemporal da dívida pública.

Em termos práticos, com a taxa de juros nominal fixada e comportamento fiscal ativo, o efeito da política monetária sobre os preços depende de como a autorida de fiscal ajusta os impostos diretos, em resposta aos movimentosda dívida real. Quando os impostos não acomodam a elevação da dívida, contrações monetárias imprevistas imediatamente aumentam as taxas de juro nominais e a dívida real, além de diminuir os saldos reais. Nesse caso, os preços respondem com um lag: se há um aumento (queda) futuro dos impostos diretos, em resposta ao aumento da dívida real, a contração diminui (aumenta) a inflação corrente.

Adicionalmente, no modelo esboçado em Leeper (1991), pelo menos uma autoridade política deve defir sua variável de controle ativamente, enquanto um orçamento do governo intertemporalmente equilibrado exige que pelo menos uma autoridade defina sua variável de controle passivamente. Entretanto, se ambas as políticas são passivas, o modelo está incompletamente especificado, e a função de preços é indeterminada. Já duas políticas ativas, permitem variações independentes que violam a restrição orçamentária do governo.

Em resumo, há quatro combinações de política macroeconômica que seriam possiveis: i) Política monetária ativa e política fiscal passiva. Onde a autoridade monetária atua com alto grau de prioridade no sentido de controlar o nível de preços, reagindo fortemente no combate à inflação. Neste caso, a autoridade fiscal reage passivamente, ajustando o nível a taxa de impostos no objetivo de manter sobre controle o orçamento fiscal; ii) Política monetária passiva e política fiscal ativa. A autoridade fiscal abre mão de a taxa de tributação em relação a choques da dívida pública. Assim, o banco central desempenha o papel de acomodar tais choques, atendendo à restrição orçamentária do governo através da senhoriagem; iii) Ambas as políticas passivas. As autoridades políticas agem passivamente, obedecendo a restrição intertemporal do governo. Sem uma posição ativa de uma das partes, há infinitas trajetórias de ofertas de moeda que são condizentes com a condição de equilíbrio do modelo; iv) Ambas as políticas são ativas. Nesse caso, nenhuma das autoridades políticas atende à restrição orçamentária, não sendo possivel gerar um equilíbrio estável no qual os agentes estejam dispostos a financiar a dívida por meio da aquisição de títulos públicos.

Posteriormente, a visão de que a inflação é um fenômeno puramente monetário é questionada por economistas que compartilham das ideias que foram formalmente agrupadas no que se convencionou chamar de Teoria Fiscal do Nível de Preços (TFNP). Entre outros, temos os trabalhos de Cochrane $(1998,2001)$ e Woodford $(1994,1995,2001)$. Kocherlakota e Phelan (1999) que argumentam que para a TFNP, há uma grave falha na visão de que o crescimento do nível de preços é simplesmente a diferença entre os crescimentos da oferta de moeda e do produto ao longo do tempo. O questionamento levantado, no caso, seria de que a quantidade de moeda que os agentes gostariam de reter no presente depende fundamentalmente das expectativas dos mesmos acerca da inflação no futuro. Dessa forma, essa relação abriria espaço para um amplo número de equilíbrios da trajetória temporal da inflação, que iriam além da simples relação entre oferta de moeda e quantidade de bens 
produzidos. Teríamos, portanto, que regras de política monetária do tipo contido em Taylor (1993) sozinhas, seriam insuficientes para controlar o nível de preços.

De acordo com Basseto (2008), "a teoria fiscal do nível de preços descreve as regras de política fiscal e monetária, tais que o nível de preços é determinado pela dívida pública, pelos tributos presente e futuros e pelos planejamentos de gastos, sem influência direta da política monetária" (BASSETO, 2008,), que por sua vez, desempenharia um "papel indireto". Nesse caso, preços são determinados pela autoridade fiscal através da seguinte relação de restrição orçamentária do governo:

$$
\frac{B_{t}}{P_{t}}=\text { valor presente dos superávits primários do governo. }
$$

Onde Bt representa o valor nominal das obrigações do governo (dívida e estoque de moedas) no período $t$ e $P_{t}$ é o nível de preços para o período correspondente. Nas palavras de Woodford (1996), "um aumento no valor presente do déficit do governo, aumenta o valor presente do consumo total que a família representativa pode pagar. Se os preços e as taxas de juros não mudam, isso induz a um aumento na demanda agregada de bens (para os preços dados)" (WOODFORD, 1996). No caso em que o Tesouro assume um superávit primário exógeno, isto é, não comprometido com a estabilidade de seu passivo real no valor presente, o equilíbrio será dado por um aumento no nível de preços, e é definido em Woodford (1995) como um regime fiscal não-ricardiano. Assim, a TFNP apresenta uma condição de equilíbrio para a restrição intertemporal do governo que definirá o comportamento da inflação, ou seja, há um único preço de equilíbrio para um dado valor presente de superávit primário e dívida nominal transmitidos de períodos passados (Basseto, 2008).

Pode-se concluir, portanto, que a TFNP nada mais é do que uma condição específica de dominância fiscal, no sentido que a autoridade monetária independente e voltada para a estabilidade de preços não é garantia para que não ocorra uma aceleração inflacionária (ROCHA E PASCHOALOTTO, 2004).

Ainda segundo Basseto (2008), dentro dessa abordagem teórica, o papel da autoridade monetária, na determinação do nível preços, seria o de afetar a evolução da dívida pública nominal através da taxa de juros definida pelo Banco Central ${ }^{5}$.

Seguindo a trajetória da literatura sobre coordenação entre políticas monetária e fiscal, é válido citar o conjunto de trabalho sobre dominância fiscal que destaca o papel do risco de default como mecanismo sob o qual a autoridade monetária de um país emergente, que adota o regime de metas de inflação, pode vir a perder o controle sobre o nível de preços. Destacamse, nessa linha, dois importantes trabalhos, ambos fazendo referência empírica à economia brasileira do período que compreende as eleições de 2002. São eles os trabalhos de: Favero e Giavazzi (2004) e de Blanchard (2004).

Favero e Giavazzi (2004) chamam a atenção para a elevada volatilidade do risco país da economia brasileira entre os anos de 2002 e 2003, e como algumas variáveis econômicas, sobretudo a taxa de câmbio, flutuam paralelamente ao risco. Haveria no caso, um circulo vicioso propagado na economia brasileira através do risco de default. Uma vez observado uma elevação nessa variável, ter-se-ia, como consequência da interrupção do fluxo de capital, uma depreciação do câmbio e aumento da razão DLSP/PIB, na época fortemente indexada ao dólar. Considerando que a desvalorização e o aumento da dívida (devido à possibilidade de monetização da mesma) desencadeiam uma elevação nas expectativas inflacionárias, tem-se

${ }^{5}$ Outros trabalhos que sintetizam a abordagem desenvolvida pela TFNP, bem como críticas recebidas, são: Christiano e Fitzgerald (2000) e Kocherlakota e Phelan (1999). 
também um efeito positivo de um choque de risco sobre a taxa de juros usada como instrumento de política monetária.

A taxa de juros de longo prazo, por sua vez, seria afetada pelo risco por dois canais, um indireto, através do aumento da taxa de política monetária (uma resposta ao aumento da inflação) e outro direto, que seria o prêmio de risco exigido pelos investidores. No caso do trabalho de Favero e Giavazzi (2004), a taxa de juros de curto prazo de referência seria a SELIC e os títulos de longo prazo tinham média em torno de 18 meses, fato este que mereceu destaque pelos autores, devido ao curto período de maturação dos títulos de mais longo prazo, dada a dificuldade do tesouro nacional em emitir dívidas de prazos mais longos.

Em seguida, os autores consideram que o prêmio de risco para países emergentes está aparentemente correlacionado a fatores internacionais, como por exemplo, o apetite dos investidores ao risco. Uma boa proxy para a variável seria o spread entre o índice de juros dos títulos de dívida das empresas americanas e a taxa de juros dos títulos americanos, os $T$ bonds. Desta forma, são exibidas evidências empíricas que sugerem uma correlação positiva entre o "U.S. corporate spread" e o EMBI Brazil. Porém, quando há um superávit primário grande o suficiente para manter constante a relação DLSP/PIB esse efeito é abrandado, o oposto acontece quando a situação fiscal é frágil, ocorrendo um agravamento do efeito.

Dadas as relações descritas acima, um choque financeiro internacional pode levar a um equilíbrio ruim da economia emergente de acordo com a seguinte dinâmica: dado o curto prazo de maturação da dívida pública, um aumento na taxa básica de juros de curto prazo eleva o custo com os serviços da dívida. Se o superávit primário não tiver seu valor elevado após o choque, sucede o aumento da razão DLSP/PIB e do índice de risco país, o EMBI. O aumento do spread prejudica ainda mais a situação da dívida pública, principalmente se se considerar o efeito da depreciação cambial (cujo impacto vai depender da estrutura da dívida pública). Como a depreciação afeta as expectativas inflacionárias e, num segundo momento, o próprio índice de preços, há, em uma economia sob o regime de metas de inflação, uma elevação da taxa básica de juros e, consequentemente uma nova pressão sobre os serviços da dívida, configurando o circulo vicioso citado pelos autores.

O que chama atenção, nesse caso, é, portanto, que sob essa configuração de dominância fiscal, um aumento da taxa de juros pode levar a um aumento da inflação, ao invés do seu efeito esperado, que por sua vez, seria o de uma redução do nível de preços.

Favero e Giavazzi (2004), portanto, utilizando a economia brasileira como referencial, realizam um estudo empírico que sugere um resultado semelhante ao de Blanchard (2004), o qual será tratado adiante. Segundo os autores, no período próximo às eleições de 2002 , se percebe que o risco de default é o centro do mecanismo que explica como o BACEN pode se afastar das metas de inflação. Assim sendo, para os autores, o risco de default cria as condições para que a economia possa passar de uma situação de dominância monetária para uma situação de dominância fiscal quando a dívida ultrapassa um patamar específico- uma relação DLSP/PIB de 56\% no caso específico.

Por conseguinte, é relevante expor as contribuições de outro importante trabalho que destaca a importância do risco de default no processo que leva uma economia a operar em uma situação de dominância fiscal. Trata-se de Blanchard (2004). Em seu artigo, Fiscal dominance and inflation targeting: Lessons from Brazil, o economista discute os efeitos de uma política monetária restritiva em um regime de metas de inflação sobre um desenho que compõem alta relação DLSP/PIB, expressiva indexação da dívida pública a moedas estrangeiras e alto grau de aversão ao risco por parte dos investidores internacionais.

Nesse contexto, um aumento da relação DLSP/PIB, devido à elevação da taxa de juros, desencadeia um incremento na percepção de risco, incidindo em uma fuga de capitais que provocaria uma desvalorização cambial e por fim, pressionaria a inflação. Assim, ter-se-ia outra caracterização da dominância fiscal, que seria verificada devido à ineficiência da 
política monetária no controle da inflação face aos desajustes fiscais e um ambiente de alta aversão ao risco. Uma situação indesejada que afetaria, sobretudo, uma economia emergente sob o regime de metas de inflação, na qual a manutenção de seus títulos em portfólios é considerada, pelos investidores, uma estratégia de risco.

Neste caso, como se observa, a política monetária perde o controle sobre a inflação e é dominada pelas expectativas a respeito das condições fiscais. Blanchard (2004) sugere empiricamente que a economia brasileira passa por esse tipo de dominância fiscal entre os anos de 1999 e 2004, sendo a "probabilidade de default" o fator que suscita tal relação entre as políticas econômicas. Ainda segundo o mesmo trabalho, os resultados empíricos reforçam as conclusões de a economia estará mais apta a tal resultado quanto maior for o estoque inicial da dívida, mais alta a proporção da dívida denominada em moeda estrangeira e maior a aversão ao risco dos investidores estrangeiros. Portanto, da mesma forma que os resultados anteriores, o trabalho pode ser considerado uma ferramenta teórica e empírica em apoio àqueles que advogam que uma condição fiscal austera é bem-vinda para tornar o regime de metas de inflação eficiente no seu objetivo de controle do nível de preços e manutenção da estabilidade dinâmica da economia.

Tais reflexões a respeito da coordenação de políticas macroeconômicas nos possibilitam deduzir que há na regra de Taylor, limitações no que tange a garantir a estabilidade de uma economia no longo prazo, principalmente em uma economia emergente. Sendo assim, seria possível propor uma regra mais adequada aos problemas levantados nessa seção, com a inserção de variáveis fiscais na função de reação do Banco Central ou até mesmo com a criação de uma função de reação para a política fiscal, objetivando regras mais claras, que tomariam o espaço das políticas discricionárias também nessa esfera da política econômica.

Tem-se aqui, uma importante linha de pesquisa ainda aberta e que necessita ser explorada com mais rigor, como será comentado na sequência. Vale a pena lembrar que tais regras podem levar em conta não só o nível de preços para a condução do resultado primário do governo, como o desvio da produção agregada observada do seu nível potencial.

\section{QUESTÕES ABERTAS A RESPEITO DA INTERAÇÃO ENTRE POLÍTICA MONETÁRIA E FISCAL.}

Em seu polêmico artigo, Blanchard et ali (2010) colocam em cheque uma séries de questões a respeito das políticas macroeconômicas que supostamente já estavam consolidadas nas últimas duas décadas e arriscam sugestões do que estar por vir em termos de pesquisas para a área referida.

Mais especificamente os autores questionam o fato de que "nos pensávamos" a política monetária como tendo um objetivo, a inflação, e um instrumento, a taxa de juros de política. Sendo assim, a política monetária teria feito seu trabalho quando manteve a inflação estável e como resposta, o gap do produto seria pequeno e também estável. Neste contexto, a política fiscal seria destinada a um papel secundário, devido a suas restrições políticas (necessidade de manter superávits) e a regulamentação financeira, por sua vez, nem se quer faria parte do quadro de políticas macroeconômicas. Uma vez que a política monetária garantisse a estabilidade do produto, não haveria razões para o uso da política fiscal como instrumento de políticas anticíclicas. Toda essa confiança nos aparatos da política macroeconômica foi reforçada, segundo os autores, pelo fato estilizado que ficou conhecido como "grande moderação". Este, por sua vez, consistiu no declínio da variabilidade do produto e da inflação na maior parte dos países de economia avançadas entre a década de 1990 e a crise financeira de 2007/2009.

De fato, a maior parte da revisão teórica apresentada nesse artigo corrobora o diagnóstico colocado no parágrafo acima. Contudo, o advento da crise financeira mundial 
coloca em contestação, pelo menos de forma parcial, a consolidação do conhecimento acerca de política macroeconômica. Segundo Blanchard et al. (2010), uma inflação estável é condição necessária, porém não suficiente, para uma trajetória de crescimento sustentado. Entre os motivos para essa posição crítica a respeito da macroeconomia está a questão de que o índice de inflação pode não refletir adequadamente o desequilíbrio de mercado sinalizado por aumentos abruptos em ativos específicos (preço do petróleo e das habitações), por exemplo. Abre-se assim, um espaço para a importância das intermediações financeiras, para a conscientização a cerca do perigo das bolhas de ativos e, consequentemente, para a não neutralidade da regulamentação financeira. Um segundo fator seria que uma taxa de inflação baixa é, em geral, concomitante a uma baixa taxa de juros nominal, impondo uma restrição à política monetária e fazendo ressurgir a relevância da política fiscal, principalmente quando se considera recessões com períodos mais longos em que o estímulo fiscal teria tempo suficiente para produzir resultados benéficos.

Ainda respeito da necessidade de se repensar o papel da política fiscal, Romer (2011) coloca que há uma crescente literatura empírica que investiga os efeitos desta política no curto prazo. O consenso chegado nessa área foi o de que uma redução na tributação e aumento nos gastos públicos elevam o produto no curto prazo. Porém, algumas questões cruciais ainda estão abertas, como: a magnitude e o timing desses efeitos, os canais de transmissão da política e se estes são dependentes do estado da economia. Assim, segundo o autor, todas essas questões estariam em um estagio inicial.

Também na tentativa de fomentar o debate acerca dos limites da teoria macroeconômica vigente e identificar novos caminhos para a pesquisa correlata, Blanchard et al. (2010) afirma que a crise deixou claro que a política monetária deve ter uma maior abrangência mais variada em termos de metas e que é necessário está atento para a quantidade de instrumentos oferecidos pela política monetária, fiscal e regulatória. Porém, os autores se ausentam de conclusões apressadas ao admitir que ainda levará um tempo para o amadurecimento de tais ideias.

Outra consideração importante é a de que não se trata, necessariamente, de uma mudança estrutural na macroeconomia, no sentido de que o conhecimento desenvolvido na área no período pré-crise não deve ser desprezado, uma vez que ele reflete, da melhor maneira possível, a maior parte dos fenômenos macroeconômicos. Mais especificamente, os alvos finais da política devem ser o produto e inflação; a taxa natural de desemprego é uma boa aproximação para parâmetros que devem ser considerados pelos policymakers, que por sua vez, não devem perseguir um trade-off de longo prazo entre inflação e desemprego; e a estabilidade do nível de preços deve permanecer como um dos principais alvos da política monetária. Adicionalmente, a sustentabilidade da restrição intertemporal do governo é importante não só no longo prazo, mas também para balizar as expectativas dos agentes no curto prazo.

\section{CONCLUSÕES E COMENTÁRIOS GERAIS}

O presente artigo é uma tentativa de elucidar as questões a respeito do consenso formado acerca do papel das políticas macroeconômicas e a suas interações, mais especificamente a respeito das políticas monetária e fiscal. Compreende-se que a coordenação dessas duas políticas é uma condição necessária para a estabilidade macroeconômica. Entretanto, parece ter ocorrido um amplo consenso que a política fiscal tem um papel secundário de garantir as condições para a atuação da política monetária na busca por sua meta de estabilizar o nível de preços.

De fato, o consenso mais geral se dá no sentido de abrir mão da discricionariedade em favor de regras claras que garantam o crescimento a partir do bom desempenho das variáveis 
reais, de forma geral, conseguidos a partir de ganhos de produtividade do capital e do trabalho e da alocação de recursos para o investimento, concedidos pela poupança.

Todavia, o consenso estabelecido no pré-crise financeira foi colocado, recentemente, como alvo de questionamentos. Porém, o debate levantado pelo mainstream, aparentemente não se dá no sentido de representar uma mudança de paradigmas dentro da teoria macroeconômica, mas sim no caminho de adequações a falhas e negligencias cometida pelo consenso supracitado. Ainda que em estágio inicial, essas adequações estão sendo desenhadas no propósito de retomar um papel mais importante para a política fiscal, aumentar o escopo da política monetária (detecção de novos instrumentos e de mecanismos de flexibilização das metas), bem como da inserção da regulação financeira na agenda da pesquisa macroeconômica e na formulação de políticas. 


\section{REFERÊNCIAS}

BALL, L. Policy rules for open economies. In Taylor, J., Monetary Policy Rules, pp. 127-44. The University of Chicago Press, London, 1999. http://www.nber.org/chapters/c7415.pdf

BASSETO, M. Fiscal Theory of the Price Level, in Lawrence Blume and Steven Durlauf (eds.), The New Palgrave: A Dictionary of Economics, 2nd edition, MacMillan: London.2008. http://users.nber.org/ bassetto/research/palgrave/ftheorypost.pdf

BLANCHARD, O. Fiscal dominance and inflation targeting: Lessons from Brazil, NBER Working Paper Series, Cambridge, MA: MIT Press, Working Paper 10389, 2004. http://www.nber.org/papers/w10389.pdf?new_window=1

BLANCHARD, O. Rethinking Macroeconomic Policy, IMF Staff Position Note,2010. http://www.imf.org/external/pubs/ft/spn/2010/spn1003.pdf

CARLIN,W.; SOSKICE,D. Macroeconomics: Imperfections, Institutions and Policies. Oxford University Press. 2006.

COCHRANE, J. A frictionless view of U.S. inflation. NBER Macroeconomics Annual, Cambridge, MA: MIT Press, p. 1998. http://www.nber.org/papers/w6646.pdf?new_window=1

. Long-term debt and optimal policy in the fiscal theory of the price level. Econometrica, v. 69, n. 1, p. 69-116, 2001.

http://faculty.chicagobooth.edu/john.Cochrane/research/papers/Cochrane\%20Long\%20Term \%20Debt\%20(Econometrica).pdf

CORREA, A.S.; MINELLA,A. "Nonlinear mechanisms of the exchange rate passthrough: A Phillips curve model with threshold for Brazil," $\underline{\text { RevistaBrasileira de }}$ Economia, Graduate School of Economics, Getulio Vargas Foundation (Brazil), vol. 64(3), pages 231-243, September,2010. http://www.scielo.br/pdf/rbe/v64n3/a01v64n3.pdf

FAVERO, C.; GIAVAZZI,F. Targeting inflation when debt and risk premia are high: lessons from Brazil. IGIER, BocconiUniversity, May. Mimeo, 2003. http://www2.dse.unibo.it/seminari/giavazzi.pdf

GANDOLFO, G. Economic Dynamics, Nova York: Springer Study Edition, 1997.

GOLDFAJN, I.; WERLANG,W. The pass-through from depreciation to inflation: a panel study, Banco Central do Brasil working paper series, 2000. http://www.bancocentral.gov.br/pec/wps/ingl/wps05.pdf

KYDLAND, F.; PRESCOTT, E. Rules rather than discretion: the inconsistencyof optimal plans. Journal of Political Economy, n.85, 1977. http://www.sfu.ca/ kkasa/prescott_77.pdf

KOCHERLAKOTA,;N. PHELAN,C. "Explaining the fiscal theory of the price level," Quarterly Review, Federal Reserve Bank of Minneapolis. 1999. http://www.minneapolisfed.org/research/qr/qr2342.pdf

LEEPER, E. M. Equilibria under active and passive monetary and fiscal policies. Journal of Monetary Economics, v. 27, n. 1, p. 129-147, 1991.

http://www.sciencedirect.com/science/article/pii/030439329190007B

Anchors away: how fiscal policy can undermine the taylor principle, NBER Working Paper Series, Cambridge, MA: MIT Press, Working Paper 15514, NBER, 2009. http://www.nber.org/papers/w15514.pdf?new_window $=1$

ROCHA, F. F.; PASCHOALOTTO, E. Teoria fiscal do nível de preços: um teste para a economia brasileira no período1966/2000. Pesquisa e Planejamento Econômico, Rio $\begin{array}{llll}\text { de Janeiro, } & \text { v. 34(3), } & \end{array}$ http://www.memoria.nemesis.org.br/index.php/ppe/article/viewFile/74/48 
RIGOLON, F.J.Z. Regras de política monetária ótimas em pequenas economias abertas. Concursos de monografias $B A C E N$,

2003.http://www.bcb.gov.br/htms/sobre/consursomonografia/francisco.pdf

SARGENT, T. WALLACE, N. Some unpleasant monetarist arithmetic. Quartely Review, Federal Reserve Bank of Minneapolis, p. 1-17, 1981. http://www.minneapolisfed.org/research/qr/qr531.pdf

SVENSSON, L. "Open-economy inflation targeting", Journal of International Economics50, 155-83, 2000. http://www.sciencedirect.com/science/article/pii/S0022199698000786

TAYLOR, J.B. "Discretion versus Policy Rules in Practice," Carnegie-Rochester Conference Series on Public Policy, 39, pp. 195-214, 1993. http://www.stanford.edu/ johntayl/Papers/Discretion.PDF

WOODFORD, M. Monetary policy and price level determinacy in a cash-inadvance economy. Economic Theory, v. 4, n. 3, p. 345-380, 1994.

.Control of Public Debt: A Requirement for Price Stability, NBER Working Paper, 5684, 1996. http://www.nber.org/papers/w5684.pdf?new_window=1

.Price-level determinacy without control of a monetary aggregate. Carnegie-Rochester.Conference Series on Public Policy, v. 43, p. 1-46, 1995.

Fiscal requirements for price stability. Journal of Money, Credit and Banking, v. 33, n. 3,p. 669-728, 2001. 